\title{
Characterization of Strength-Shift Behavior of Bolts Connected with and without Preloading
}

\author{
A. Trindade \\ Departamento de Engenharia Mecânica e Gestão Industrial, Instituto Politécnico de Viseu, Portugal
}

\begin{abstract}
Bolted joins allow for more efficient joining of parts (mechanical and structural components) when assembly and disassembly, called interchangeability, are concerned. Also and for this reason, they are the most widely used in the final assembly, already in construction, in a state of final consolidation of the structure. This work began in a pedagogical action to compare the experimental results with those obtained by Eurocode 3 (EN 1993-1-8) in simple joints with screws subject to cutting, the study evolved the analysis of the behavior of the screws themselves in the joint .Tests were carried out with great dimensional accuracy, for new bolted connections, with different bolt's number, according to different arrangements and repeated in cases of simple and preloaded tightening. The experimental work, carried out on a uniaxial tensile testing machine, consisted in subjecting the connections to a growing effort so that the bolts, being subject to the cut, would break through the thread-free zone. The analysis of results and their comparison (in force-displacement diagrams) allow drawing conclusions regarding the true behavior of the bolted connections. The characterization of the thresholds of the initial zone of the force-displacement curves, in the cases of connections with preloading - was the objective of study. The transfer of forces and the influence of friction on the bonds without and with preloading were then characterized. The main objective of this project is to know the meaning of the calculated values in the preloaded and non-preloaded links by Eurocode 3.
\end{abstract}

Key words: Bolts, connections, collapsible, preloading, Eurocode 3.

\section{Introduction}

Bolted connections and welded connections are widely used in factory buildings and in the field of metal structures. It is very common to use soldering in the common permanent connections made in the factory and the most commonly used bolts in the outer detachable connections.

The advantages of using bolted connections are:

- Speed of execution of overseas connection.

- The manpower used for the installation and inspection of the bolts does not need to be as specialized as the one used in welded connections.

- The installation equipment is simple and does not require much energy for the confection of the joint and the bolting.

On the other hand, the disadvantages of bolted

Corresponding author: Adelino Trindade, adjunt professor, $\mathrm{Ph} . \mathrm{D}$., research fields: mechanical engineering, design of joins, manufacturing processes. email: atrind@estv.ipv.pt. connections are:

- The existence of the holes implies a reduction in the resistance of the connected parts and, sometimes, it is necessary to reinforce them.

- The connections are more complex than welded connections and require more calculation, detailing and manufacturing work.

- The need for early verification to avoid mismatched holes and lack of bolts in the work [1].

Bolted connections can be classified according to the types of forces acting on the bolts: can be tensile, shear, or a combination of both. In Fig. 1 there are some connecting joints which introduce shear stress into the bolts:

(a) Shows a connection between bars where the stress on the joint is traction;

(b) Joints in compression of a knot of a trellis;

(c) Joint of a support subject to torsion;

(d) Joins in simple bending of the connection between a beam and a column. 


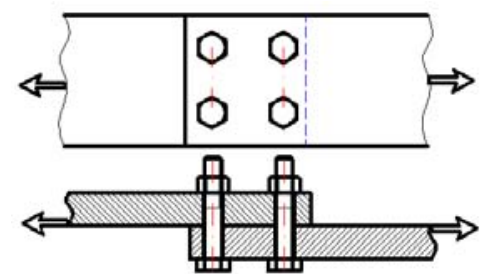

(a)

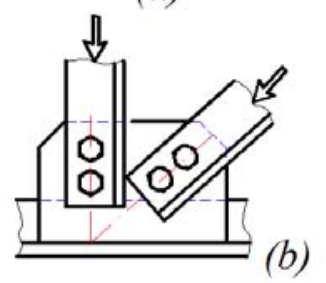

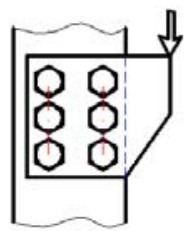

(c)

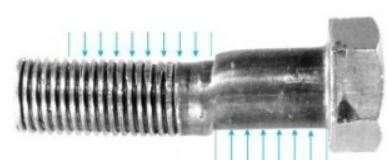

(a)

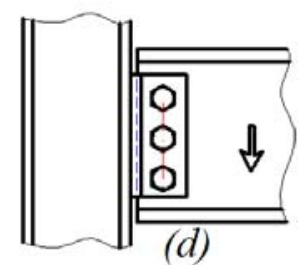

Fig. 1 Examples of bolted connections.

Other consequences for the joint materials are presented in the remaining images of Fig. 2, where Fig. $2 \mathrm{~b}$ shows a case of hole deformation due to compression, in Fig. 2c a tear is seen from the bore and in Fig. $2 d$ the tearing of the plate is seen due to the necking caused by traction and the section is not sufficient.

Regardless of the bolt's number, the type of engagement in the joint Fig. 1a may have the consequences shown in Fig. 2a, noting that the shearing forces acts in a plane transverse to the axis of the bolt, whose area of the resistant section is measured in the non-threaded zone.

The objective of the study carried out and presented here was: analysis of the behavior of the bolts to the cut, in a simple joint of connection as in case (a); verification of the importance of the location of the bolts in the joint and the calculation of resistance forces by Eurocode [2]; comparison between these results with those obtained experimentally, through a force-displacement diagram for the test pieces.

The basic condition prescribed for a bolted connection, subject to traction, is that the request be transferred to secure the bolts to the cut. Alternatively, there may be a transfer by frictional contact between the surfaces of the interface of the test pieces by the compression imposed by the pre-stress applied prior to the bolts. In this case, the bolts will not be subject to shear if the slip resistance between the components of the connection due to friction [3] is not exceeded.

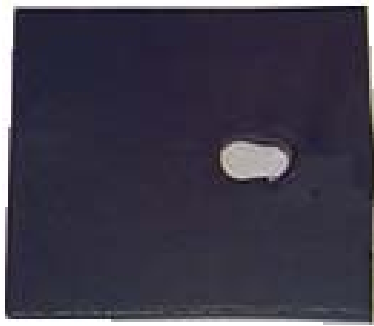

(b)

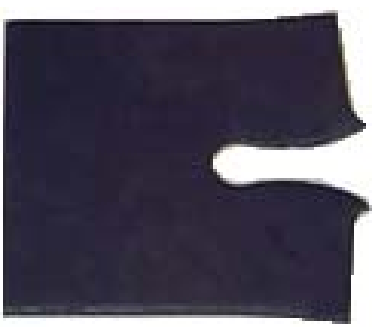

(c)

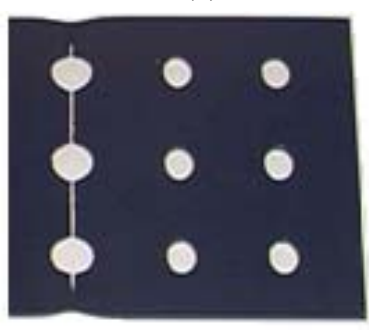

(d)
Fig. 2 Failure modes due to the joint being subjected to cutting. (a) bolt to cut, (b) deformation of the hole due to compression, (c) tearing of the hole, (d) tearing of the plate due to traction.

\section{Study Cases}

\subsection{Work Planning}

The study and comparison of the resistance of bolted connections by simple overlap with a sliding plane made with M6 partially threaded bolts bolted in two different ways, some without and others with preloading were made through the following cases:

- A: use of 1 bolt.

- B: use of 2 bolts aligned with the loading direction.

- C: use of 3 bolts aligned in the transverse direction to the loading direction.

- D: use of 3 bolts aligned with the loading direction.

- E: use of 3 bolts aligned with an inclined direction relative to the loading direction.

- F: use of 3 bolts arranged in an equilateral triangle.

The essential question in this work is to analyze the resistance values calculated by the Eurocode 3 with respect to what happens in reality in a diagram force-relative displacement of the constituents of the test pieces. 
As far as possible, the provisions of Eurocode 3 have been followed. The nominal diameter of the bolts used in structural connections must be at least M12, unless otherwise specified, that the minimum diameter (EN 1090-2: 2008) [4]. However, due to experimental factors, justified later, only bolts with a nominal diameter of $6 \mathrm{~mm}$ were studied.

The resistance to slip of a connection with high resistance bolts, subject to the shear force, is obtained by Eurocode for a cutting plane and for one bolt.

For bolted connections with pre-stress, according to the Eurocode, the bolts to be used must be of high strength, of classes 8.8 or 10.9 , and the contact surfaces must meet one of the conditions given in Table $1[1,2]$. In this work, the surfaces are presented as laminated and, therefore, of class D.

The loading of all the test pieces followed an analogous scheme, as schematized in Fig. 3, being subjected to a tensile loading until the breakage bolts of the connection were cut.

In Fig. 1, there is a slippage between the slabs, whose resistance to sliding depends on the preloading and friction values; while on the double-cut, with two planes of cut, there are two levels. After total slippage, all resistance versus displacement curves, with or without pre-stress, tends to converge with one another [5].

Table 1 Classification of friction surfaces (EN 1090-2).

\begin{tabular}{lll}
\hline Superficial treatment & Class & $\begin{array}{l}\text { Friction } \\
\text { coef. }\end{array}$ \\
\hline $\begin{array}{l}\text { Pickling surfaces with steel shot or } \\
\text { sandblast, without oxidation or corrosion }\end{array}$ & A & 0.5 \\
$\begin{array}{l}\text { Pickling surfaces with steel shot or } \\
\text { sandblast and coated }\end{array}$ & B & 0.4 \\
$\begin{array}{l}\text { Clean surfaces with brushed steel or } \\
\text { flame-free, no oxides. }\end{array}$ & C & 0.3 \\
Surfaces such as rolled & D & 0.2 \\
\hline
\end{tabular}

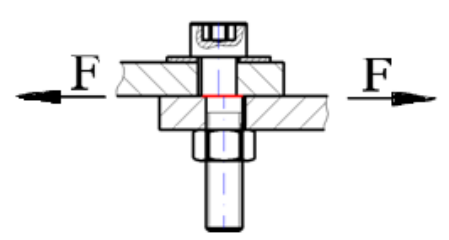

Fig. 3 Bolted connection diagram with a bolt fastened to the cut.

\subsection{Calculation of the Value of Slip Resistance According to Eurocode}

In the verification of the strength of the M6 bolts of class 8.8 , subject to cutting, in the states without and with preloading, according to norm NP 1993-1-8 (Eurocode 3 or EC3), the following parameters and expressions were considered that are presented below:

In terms of dimensioning, the fundamental condition is that the value of the transverse stress in the applied limit state is smaller than the value of calculation of the resistance to the transverse stress of the bolts:

$$
\begin{aligned}
& F_{v . E d} \leq F_{v . R d} \\
& F_{v . E d} \leq F_{S . R d}
\end{aligned}
$$

where:

- $F v, R d$ is the maximum design strength that each bolt can withstand being subject to shear;

- $F \mathrm{~s}, R d$ is the design slip resistance to which each pre-stressed bolt is supposed to withstand cutting.

Test pieces with non-preloaded bolts are simple-tightening with a tightness of $3 \mathrm{kN}$ to ensure a rigid connection, while those with pre-stressing application calculated according to ratio (3), which gives:

\begin{tabular}{|c|c|c|}
\hline Features for sizing bolts & Class & 8.8 \\
\hline Factor defined in the appropriate table & $\propto_{v}$ & 0.6 \\
\hline $\begin{array}{l}\text { Tensile yield strength of the bolt } \\
\text { material }\end{array}$ & $f_{y b}$ & $640 \mathrm{~N} / \mathrm{mm}^{2}$ \\
\hline Ultimate strength of the bolt material & $f_{u b}$ & $800 \mathrm{~N} / \mathrm{mm}^{2}$ \\
\hline Nominal diameter & $d$ & $6 \mathrm{~mm}$ \\
\hline $\begin{array}{l}\text { Nominal cross-sectional area of bolt } \\
d=6 \mathrm{~mm}\end{array}$ & $A$ & $28.27 \mathrm{~mm}^{2}$ \\
\hline $\begin{array}{l}\text { Area of the gross cross-section of the } \\
\text { threaded area of the bolt } \\
d=5.059 \mathrm{~mm}\end{array}$ & $A_{s}$ & $20.1 \mathrm{~mm}^{2}$ \\
\hline $\begin{array}{l}\text { Parameter whose value can be taken } \\
\text { from Table } 3.6 \text { of EC } 3\end{array}$ & $K_{s}$ & 1 \\
\hline Number of friction planes & $n$ & 1 \\
\hline Coefficient of friction & $\mu$ & 0.2 \\
\hline \multirow{2}{*}{ Partial link security coefficients } & $\gamma_{M 2}$ & 1.25 \\
\hline & $\gamma_{M 3}$ & 1.25 \\
\hline Diameter of the holes for the bolts & $d_{0}$ & $6.4 \mathrm{~mm}^{*}$ \\
\hline
\end{tabular}

Table 2 Data used in the calculation of forces by the EC3.

* The hole with a diameter of $6.5 \mathrm{~mm}$ was used due to the available drill bit. 
Table 3 Calculation ratios by EC3 (by bolt).

\begin{tabular}{cccc}
\hline Non-preloaded & \multicolumn{2}{c}{ Preloaded } \\
\hline$F_{v . R d}=\frac{\propto_{v} * f_{u b} * A}{\gamma_{M 2}}$ (1) & $F_{p . C}=0,7 * f_{u b} * A_{s}$ & (3) \\
$A=\frac{\pi * d^{2}}{4}$ & (2) & $\begin{array}{l}\text { As }=20,1 \mathrm{~mm} \\
\left(\mathrm{~d}_{\mathrm{o}}=5 \mathrm{~mm}\right)\end{array}$ \\
$(\mathrm{d}=6 \mathrm{~mm})$ & & $F_{S . R d}=\frac{K_{s} * n * \mu * F_{p . C}}{\gamma_{M 3}}$
\end{tabular}

Table 4 Results obtained with the ratios of Table 3.

\begin{tabular}{lllllll}
\hline & $\mathrm{A}$ & $\mathrm{B}$ & $\mathrm{C}$ & $\mathrm{D}$ & $\mathrm{E}$ & $\mathrm{F}$ \\
\hline $\begin{array}{l}\text { Non-preloaded } \\
F_{v . R d}(\mathrm{~N})\end{array}$ & 10,853 & 21,714 & 32,572 & 32,572 & 32,572 & 32,572 \\
Preloaded & 1,802 & 3,602 & 5,403 & 5,403 & 5,403 & 5,403 \\
$F_{\text {s.Rd }}(\mathrm{N})$ & 1,02 & & & &
\end{tabular}

$$
\mathrm{Fp}, \mathrm{C}=11,256 \mathrm{~N}
$$

For the calculation of the shear strength, in simple clamping connections (test pieces with index 1 designation), we use Eq. (1). Since in the specimens we have cases with $\mathrm{N}=1,2$ or 3 bolts, for the calculation of the resistance to the transversal effort, then we have:

$$
\mathrm{F}_{\mathrm{v}, \mathrm{Rd}}=\mathrm{F}_{\mathrm{v}, \mathrm{Rd}}{ }^{\prime} \times \mathrm{N}
$$

and

$$
\mathrm{F}_{\mathrm{S}, \mathrm{Rd}}=\mathrm{F}_{\mathrm{S}, \mathrm{Rd}}{ }^{\prime} \times \mathrm{N}
$$

When applied, the results can be calculated for all the case studies presented in Table 4.

\section{Experimental Work}

The initial planning that was necessary for the sizing is considered in the experimental part, but there are other conditions that must be fulfilled [2]. In order not to break the components of the specimen, the distances between holes and the positions relative to the ends obey the precepts of the EC3, which are summarized in Fig. 4.

The specimens were prepared using a $50 \times 5$ bar $(\mathrm{mm})$ and the specimens were prepared by numerical control (CNC) machining with the geometries shown in Fig. 5, on one hot-rolled steel, while the designation is S 275 JR (in accordance with EN 10025-2). The distributions of bolt holes are shown in Fig. 5.

The connections were made with bolts with hexagonal hollow head (HC) whose standard designation is EN ISO 4762 M6 $\times 35-8.8$, each with its respective ISO 4032 M6-8 nut and washer on the side of the bolt head,

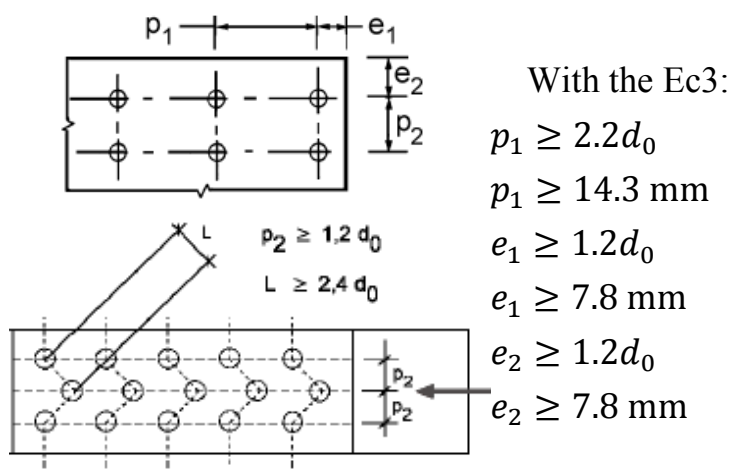

Fig. 4 Minimum dimensions of the positions of the holes between them and relative to the ends of the joint.

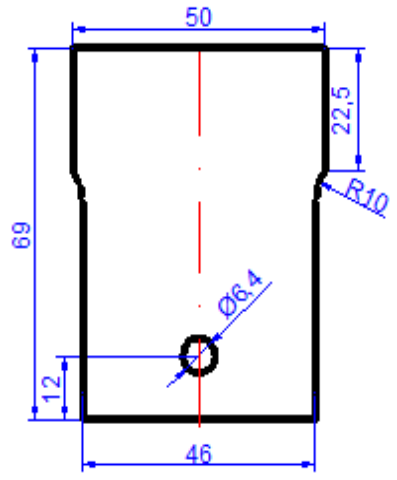

(a)

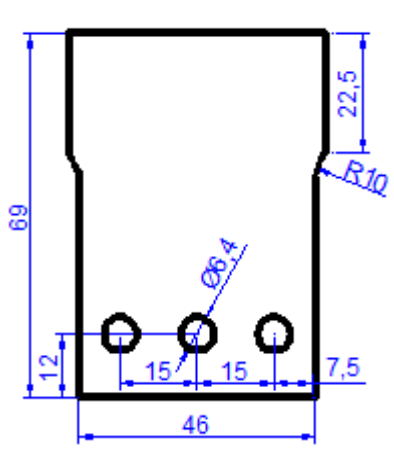

(c)

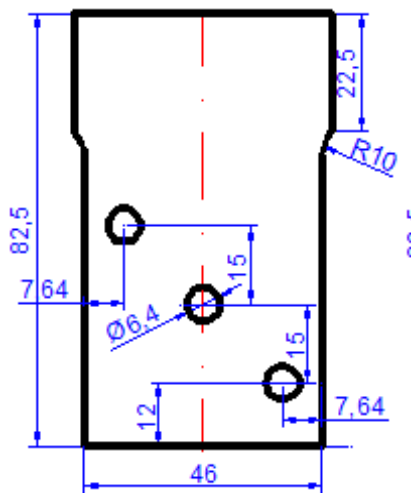

(e)

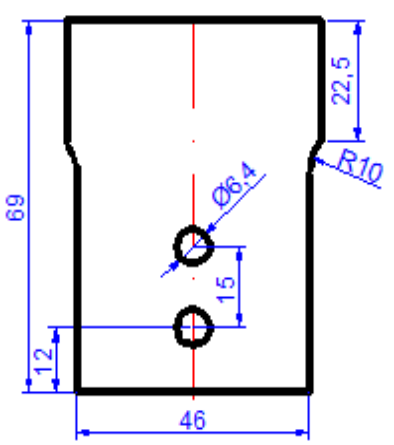

(b)

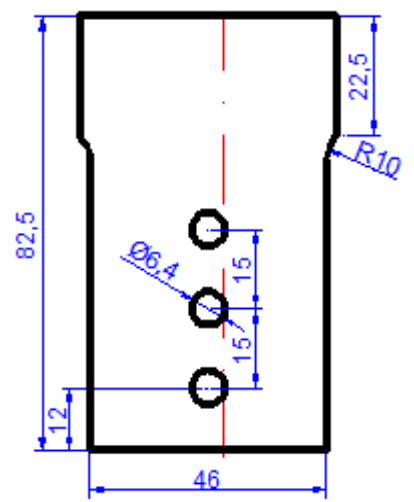

(d)

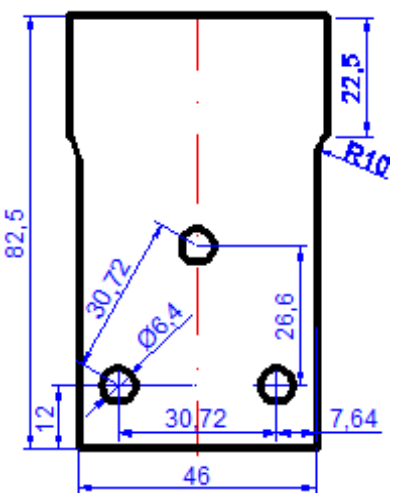

(f)
Fig. 5 Planning of the constituent parts of test pieces. 
due to its relatively small diameter. These were the bolts found on the market with a nominal diameter of $6 \mathrm{~mm}$ and a length of flat (not threaded) less than 12 $\mathrm{mm}$, corresponding to the sum of the thicknesses of the plates to be connected; and greater than $6 \mathrm{~mm}$ so that the cut does not occur in the area of the thread. The diameter measurement of the bolts gave an average of $5.88 \mathrm{~mm}$, agreeing with the values of the standard (between 5.82 and $6.00 \mathrm{~mm}$ ).

Reinforcements at both ends were welded to the components of the specimen to reduce the effect of the pulling machine claws and ensure that the action of the pull coincides with the plane of the interface of the connection.

In the preloaded cases, the nuts were tightened with tightening torque values of $\mathrm{T}=11 \mathrm{Nm}$, which was considered as an average value obtained from the ratio:

$$
T=0.2 d F_{p, C}
$$

and tables [6]. In the other cases, a representative torque of $3 \mathrm{Nm}$ was used to simulate a single tightening and all under the same conditions. In Fig. 6 is presented the planning and Fig. 7 the appearance of the test pieces for the connections with bolts without or with preloading is shown, since they are identical.

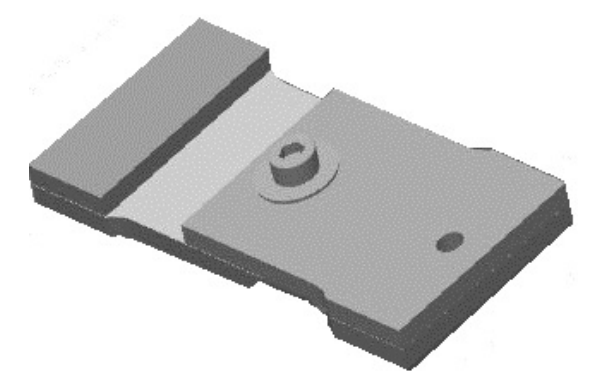

Fig. 6 3D drawing of the constitution of a test piece.

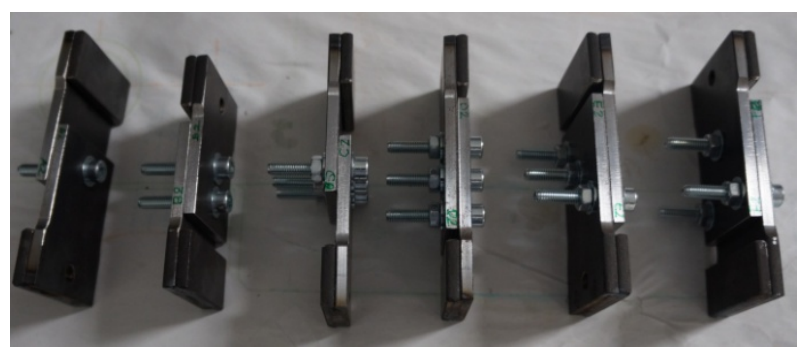

Fig. 7 Props used in the bolted connections of one of the cases of without or with preloading.

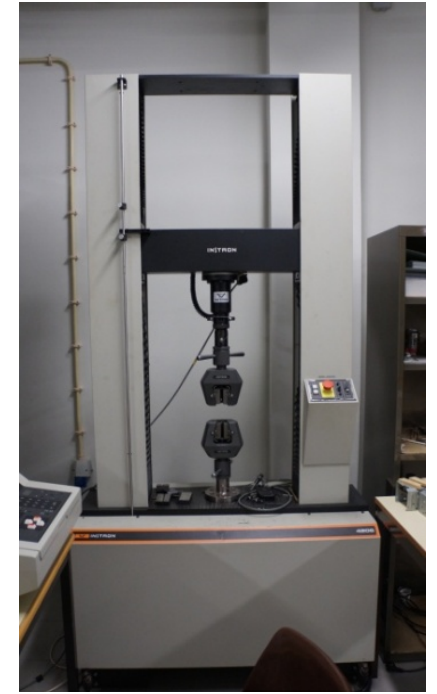

(a)

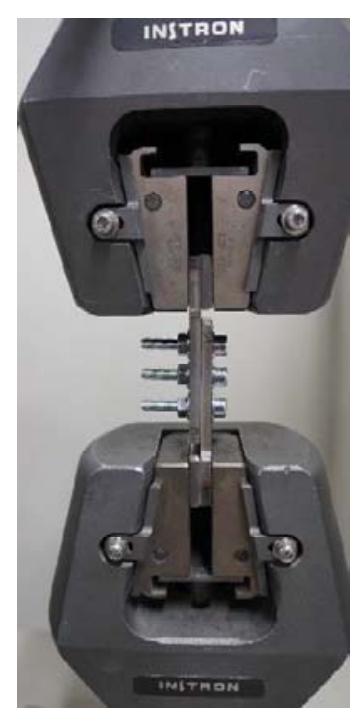

(b)
Fig. 8 Testing machine used and a detail of a specimen fixed in its claws.

In this work, the tensile testing machine used was an Instrom 4206, in Fig. 8a. Its capacity conditioned the option for bolts with a diameter of $6 \mathrm{~mm}$. If they were M12 bolts, the loads to be used would be too high and the minimum length of the non-threaded part would lead to having to use thicker bars. The claws that fixed specimens were also limited, Fig. 8b.

\section{Results Analysis}

\subsection{Fracture Mode}

As had been planned in the constitution of the test pieces, where the sum of the sections of the bolts was significantly smaller than the cross-section of the bars, and taking into account the materials of the bars and the bolts, all the bolts yielded to the cut. It was verified that in the same joint, there are bolts that present an initial phase of plastic deformation, caused by the cut, followed by fragile intergranular fracture and others where only fragile transgranular fracture occurs.

Fig. 9 shows the state of the bolts after rupture and two examples of the typical surface fracture states as mentioned. The final state of the bolts after rupture was fragile rupture, as it occurs by the rapid propagation of cracks, accompanied by little or no plastic deformation. 
Fig. 9 demonstrates that in a joint with more than one bolt, these may not be equally required. As a consequence, the bolts were yielded by fragile fracture, in a slightly different ways.

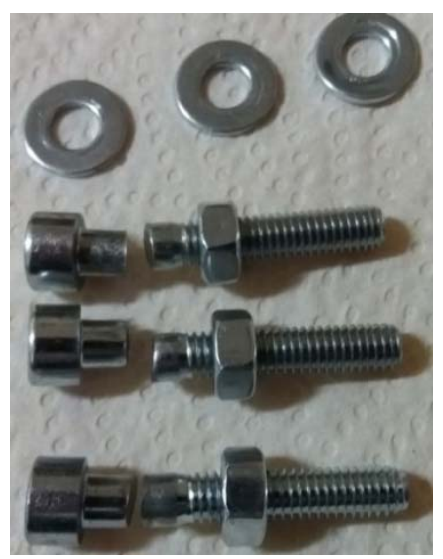

(a)

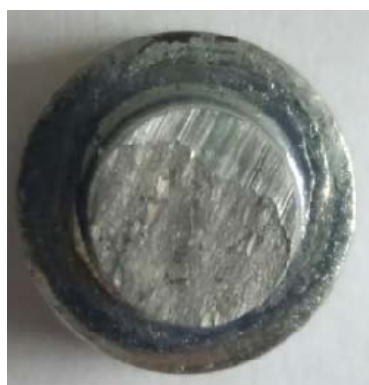

(b)

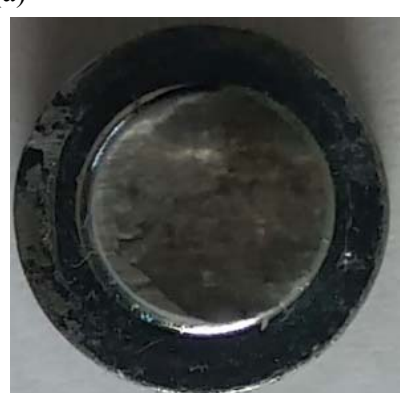

(c)
Fig. 9 Bolt condition: (a) Case of the 3 bolts of a connecting joint; (b) With significant initial cut; (c) With insignificant initial cut.

\subsection{Loading Characterization}

Load characterization comparison between values was calculated by the EC3 and the maximum load values of the experimental results are presented in the following bar chart, see Fig. 10.

The evolution of the load on the bolted joints is shown by the curves P- $\Delta$ L, in Fig. 11. Generally, the comparison of the shape of these curves, corresponding to the cases of without and with preloading, reveals behaviors approximately equal to maximum values of load on joints with equal number of bolts. However, the initial part of these curves reveals differences in the cases related to the use of preloading. In these, there is an initial delay, in the form of a landing, which is attributed to the previous tightening of the

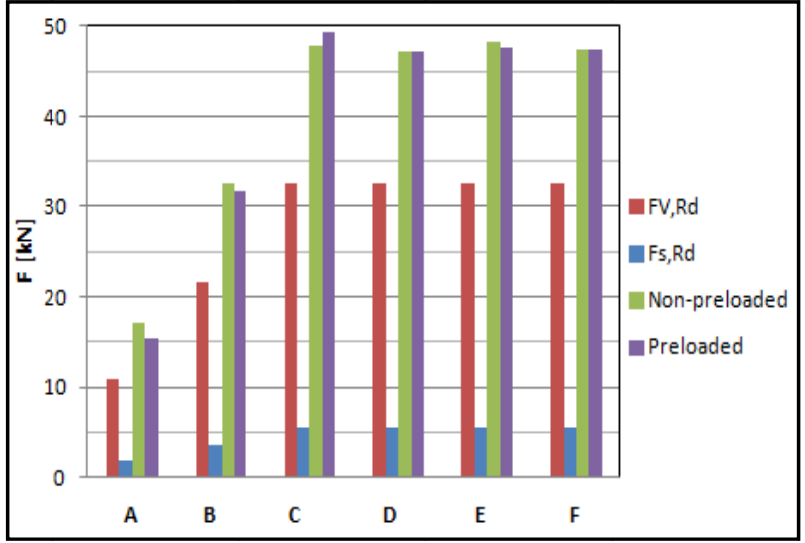

Fig. 10 Comparison of maximum load calculated by the EC3: without $\left(F_{v}, \mathrm{Rd}\right)$ and with preloading $\left(F_{s, ~ R d}\right)$ and experimental results without (simple) and with preloading.

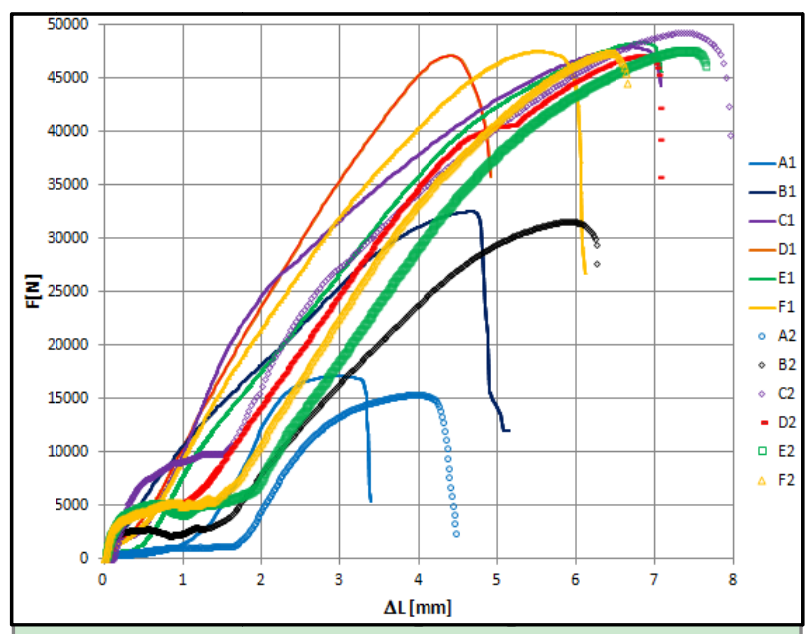

Fig. 11 Comparison of the experimental results of force-displacement of the tests carried out. Letters with index 1 (or continuous trait) are without preloading and indices 2 (or without adjusted trait) are cases with preloading.

bolts, since it is significant; hence the initial loading levels are due to the preloading. In the case of simple tightening, in the experimental data, it is verified that the maximum values of shear strength are significantly higher than those calculated by the EC3 relation and that these are located in the end zones of linear behavior.

In the characterization of a $\mathrm{P}-\Delta \mathrm{L}$ curves with preloading, 4 phases are clearly distinguished compared to only 2 phases of the non-preloading cases [1, 5, 7-11], because:

(1) The static friction hinders sliding between friction contact surfaces, this corresponds to the part 
before the initial loading threshold.

(2) The loading exceeds the friction resistance and one surface of the joint slides over the other, which defines the landing.

(3) The bolts and plates deform elastically, and the curves $\mathrm{P}-\Delta \mathrm{L}$ become practically parallel to the corresponding cases of simple loading, which justifies the linear behavior.

(4) Once the yield is exceeded, one or more elements undergo plastic deformation until the maximum tension and "fragile" breakage of the bolt, in this case.

The detailed analysis of the beginning of the loading allows better showing the effect described, as can be seen in Fig. 12. In cases without preloading, phases 1 and 2 do not exist or are insignificant.

In the cases of preloading, the resistance values calculated by the EC3 relationship are in the end region of linear behavior of the initial loading levels. These values are associated with the end of slippage of the surfaces in contact with friction. However, it can be seen that in the connections with 3 preloaded bolts, the ends of the steps do not coincide, which means that they are influenced by the arrangement of the bolts in the joint. In the comparison of connections with different arrangement of the bolts, example of Fig. 13, it is observed that they have consequences in the distortion of the bolted joint.

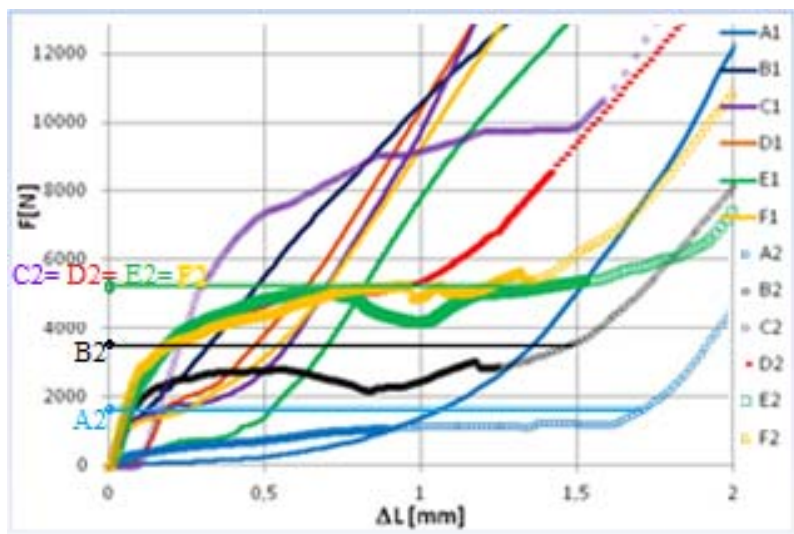

Fig. 12 Comparison of the initial phase of the experimental results of force-displacement of the tests performed and of the values calculated by EN 19931.8 .

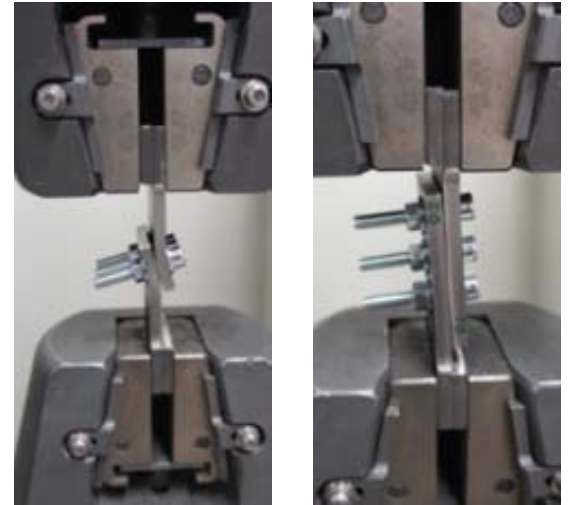

Fig. 13 Comparison of 2 cases, at the end of the test, with the same number of bolts arranged differently.

Table 5 Surface finish of the contact surfaces.

\begin{tabular}{ll}
\hline Type of surface finish & $\begin{array}{l}\text { Roughness Ra } \\
\text { average }[\mu \mathrm{m}]\end{array}$ \\
Surfaces such as rolled & 1,249 \\
Clean surfaces by sanded, no oxides & 1,002 \\
\hline
\end{tabular}

4.3 Analysis of the Influence of the Finish of the Contact Surfaces

To conclude, a brief study of the influence of friction between tests with and without preloading was carried out. For this purpose, a new test specimen was made equivalent to $\mathrm{F} 2$ but with the contact surfaces being previously sanded to change the roughness. In the roughness measurement, a Hommel Tester T1000 rugosimeter was used, 3 measurements were made on each surface, giving as average of the average arithmetic roughness values $\mathrm{Ra}$, the values are presented in Table 5.

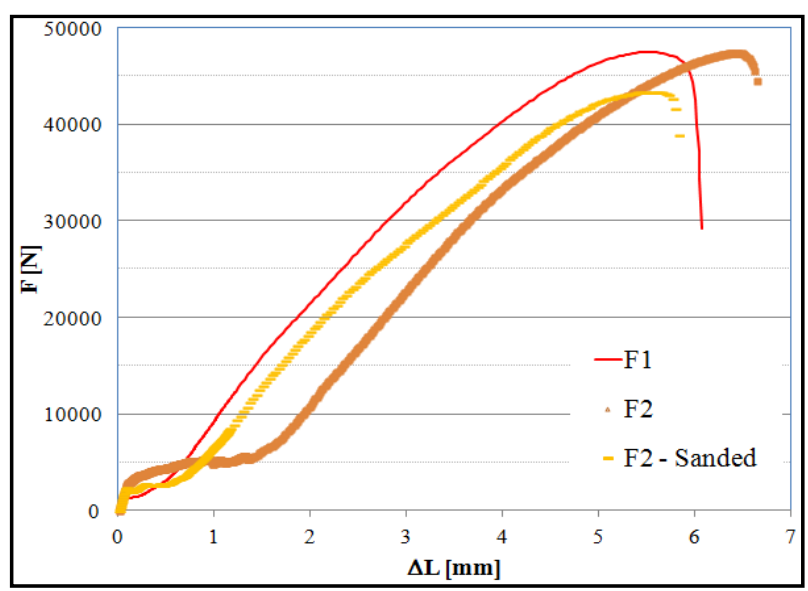

Fig. 14 Comparison of experimental results $P-\Delta L$ of the tests carried out with test pieces with 3 bolts in triangle, without and with preloading, as rolling and sanded. 
Even though the number of samples was not significant, the comparison of results on Fig. 14 shows that the size reduction of the landing must to the better surface finish (F2 sanded) and consequent lower friction.

\section{Conclusions and Future Work}

With this work, it is concluded, as expected, that the increase in the number of bolts in the bond leads to the (almost linear) increase in bond strength. In carrying out these practical tests and in the comparison with the calculated theoretical values, the following conclusions can be reached:

- In the non-preloaded connections, the shear strength calculated by the EC3 is close to the end of the almost linear part of the loading curve. In these cases, it is the bolts that support the bonding stress through their shear strength;

- For preloaded connections, the 4 typical phases of loading are verified. The calculated values of the sliding resistance by the EC3 correspond to the end of the second loading phase, in other words, the sliding-related landing due to contact with friction. However, the distribution of the bolts in the joint can change the load values that define the levels. Thereafter, the bolt also contributes to its shear strength to support the bond. Thus, in design by the EC3, it implies that the bolts do not come to a significant cutting request and then the bond will be of long duration.

- The previous conclusion leads to the following, if there is no damage to the bolts up to the value calculated in a project by the EC3, on the one hand it can be said that it is oversized, on the other it is on the security side;

While the initial loading levels due to preloading are useful in most preloaded connections, there will be others, which may be too long and cause too much joint flexibility. However, by increasing the number of bolts in the connection and the proper choice of their distribution in the joint and the accurate drilling of the holes, this flexibility can be reduced.

Future studies on bolted connections will have the following objectives:

- Check these conclusions in connection with M12 bolts.

- Perform a more complete analysis of the bolt distribution and surface condition at the joints.

- To analyze the influence of the resin injected on the bolts and their influence on the initial loading levels.

- To do studies on the influence of fatigue.

\section{References}

[1] Frantisek, W., Vratislav, M., Matthieu, M., and Zdeněk, S. 2002. "Experiments of Bolted Cover Plate Connections with Slotted Holes." CTU Reports 6 (2).

[2] NP EN 1993-1-8-Eurocode 3-Design of Steel Structures-Part 1-8: Design of Joints. 2010.

[3] www.estruturas.ufpr.br/wp-content/uploads/2015/05/Cap 3-LigaçõesParafusadas-1.pdf (1/2017).

[4] NP EN 1990-2: $2008+$ A1 2015-Execution of Steel Structures and Aluminum Structures-Part 2: Technical Requirements for Steel Structures.

[5] Carvalho, B. 2013. "Modelação por Elementos Finitos do Comportamento de Ligações Aparafusadas Sem e Com Resina Injetada.” Master's thesis, UTAD.

[6] Moura Branco, C., Ferreira, J. M., Costa, J. D., and Ribeiro, A. S. 2008. "Projeto de Órgãos de Máquinas." Fundação Calouste Gulbenkian.

[7] http://inspecaoequipto.blogspot.pt/2013/09/fraturados-ma teriais-fragil-e-ductil.html (4/2017).

[8] Bickford, J. H. 1990. An Introduction to the Design and Behavior of Bolted Joints (2nd ed.). New York: Marcel Dekker Inc.

[9] Kulak, G. L., Fisher, J. W., and Struik, J. H. A. 2001. Guide to Design Criteria for Bolted and Riveted Joints (2nd ed.), American Institute of Steel Construction, Inc.

[10] Lu, C., Ma, X., and Mills, J. L. 2014. "Modelling and Parametric Analysis of Bolted Connections on Retrofitted Transmission Tower Leg Members." Presented at the 23rd Australasian Conference on the Mechanics of Structures and Materials (ACMSM23). Australia, http://creativecommons.org/licenses/by/4.0/.

[11] McCarthy, M. A., McCarthy, C. T., and Stanley, W. F. 2011. "Bolt-Hole Clearance Effects in Composite Joints." University of Limerick, Ireland. www.researchgate.net/publication/261171874. 